\title{
Theoretical calculations meet experiment to explain the luminescence properties and the presence of defects in $m-\mathrm{ZrO}_{2}$
}

1

William Lafargue-Dit-Hauret, Romain Schira, Camille Latouche, ${ }^{*}$ and Stéphane

\author{
Jobic* \\ Université de Nantes, CNRS, Institut des Matériaux Jean Rouxel, IMN, F-44000 Nantes, \\ France \\ E-mail: camille.latouche@cnrs-imn.fr; stephane.jobic@cnrs-imn.fr
}

\begin{abstract}
The present article is a thorough quantum mechanics investigation based on DFT method targeting the opto-electronic properties of the $m-\mathrm{ZrO}_{2}$ material issuing from the presence of defects. Herein, we conclude that the luminescence observed around $477 \mathrm{~nm}(\sim 2.60 \mathrm{eV})$ corresponds to the charge transfer between $\mathrm{Ti}_{\mathrm{Zr}}$ and oxygen atoms (i.e., $\mathrm{Ti}^{3+}+\mathrm{O}^{-} \rightarrow \mathrm{Ti}^{4+}+\mathrm{O}^{2-}$ ), and not from oxygen vacancies or $d$ - $d$ transitions at $\mathrm{Ti}^{3+}$ sites. Namely, based on constrained DFT calculations, an emission at $2.61 \mathrm{eV}$ $(475 \mathrm{~nm})$ was calculated that matches perfectly with experiments (around $2.60 \mathrm{eV} /$ $477 \mathrm{~nm})$. Moreover, in order to demonstrate the propensity of the $\mathrm{ZrO}_{2}$ host lattice to entrap titanium, intrinsic and extrinsic point defect formation energies on $m-\mathrm{ZrO}_{2}$ were computed.
\end{abstract}




\section{Introduction}

In the last decades, zirconia $\left(\mathrm{ZrO}_{2}\right)$ material became particularly appealing due to its potential incorporation into a wide variety of technological devices. Thanks to its chemical and mechanical stabilities, biocompatibility, wide bandgap, high refractive index and high dielectric constant, one may find the following potential applications: semiconductor substrates, solid electrolytes, thermal barriers, sensors, gate dielectric stacks, catalysts, etc. ${ }^{1} 6$ $\mathrm{ZrO}_{2}$ may also display luminescent properties as discussed hereafter.

Formally, even though luminescent properties of $\mathrm{ZrO}_{2}$ compound have been widely reported in the literature for the different crystallographic phases (i.e., cubic, tetragonal and monoclinic), ${ }^{7-17}$ the origin of its intense white-blue emission at 470-490 nm in pure monoclinic phase $\left(m-\mathrm{ZrO}_{2}\right)$ is still a matter of debates. A tentative explanation ascribed this band to the electronic relaxation from oxygen vacancies, $\frac{10}{10}$ comforted by the observation of the decrease in photoluminescent intensity by increasing the partial oxygen pressure. $17+19$ This proposition is supported by i) EPR analyzes which confirm the existence of $\mathrm{F}^{+}$colour centers (i.e., single charged oxygen vacancies), $\underline{16[17}$ and ii) point defect calculations. $\frac{20}{20}$

Another model suggests the blue emission is induced by on-site $d$ - $d$ transitions of impurity titanium ions $\mathrm{Ti}^{3+} .12113$ Ti impurities may be naturally present as traces in $\mathrm{ZrO}_{2}$ and unintentionally substitute zirconium, since zirconium element is commonly extracted from Ti ores (e.g. ilmenite or rutile). Also, it was evidenced that the photoluminescence intensity significantly increases with titanium doping. $\frac{12|16| 21}{}$ Here, oxygen vacancies are assumed to participate to the reduction of titanium species $\left(\mathrm{Ti}^{4+} \rightarrow \mathrm{Ti}^{3+}\right)$, explaining the close connection with the enhancement of the luminescence band for crystal growths with the presence of a reducing agent. ${ }^{16}$ Surprisingly, $\mathrm{Ti}^{3+}$ species have not been identified by EPR measurements ${ }^{16}$ except at the surface of the samples. ${ }^{22}$

Other sources for the luminescence at $\approx 2.6 \mathrm{eV}$ can be found within the literature. For instance, a self-activated emission by $\mathrm{Zr}^{4+}$ sites has been pointed to be possibly responsible for. ${ }^{23}$ Another experimental study by Pan et al. concluded the charge transfer $\mathrm{Ti}^{3+}+\mathrm{O}^{-}$ 
40 $\rightarrow \mathrm{Ti}^{4+}+\mathrm{O}^{2-}$ could indeed be the main cause. ${ }^{24}$

From the theoretical side, Density Functional Theory (DFT) is usually used for inorganic solids in optics to determine band gaps, identify electronic transitions at work in a given material and get access to the complex refractive indexes. More recently, DFT has been

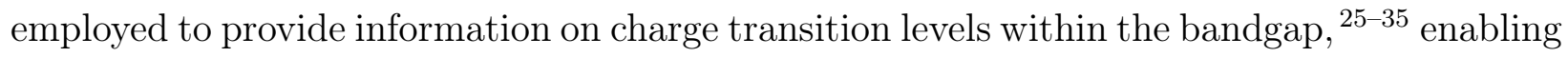
one to characterize the presence and the nature of defects in the studied structure. To our knowledge, such simulations have been reported for (only) intrinsic point defects in $m$ $\mathrm{ZrO}_{2} \cdot{ }^{20136}{ }^{44}$ Consequently, this prompted us to revisit in-depth the impact of defects (i.e., native defects and substitution of $\mathrm{Zr}$ by Ti) in $m-\mathrm{ZrO}_{2}$ on its electronic structure.

Moreover, ab initio calculations should be capable to shed light on transitions at work and anticipate the emission characteristics of solids. Unfortunately, at the opposite of molecular ab initio simulations for which the methodology is mature and (almost) routine to simulate luminescence spectra, $\sqrt{45 \sqrt[52]{52}}$ the ab initio simulation of emission spectra in solid state materials remains still challenging and a matter of some debate. Recent works demonstrated the efficiency of the $\triangle \mathrm{SCF}$ method (an efficient alternative to TD-DFT) based on the constrained DFT (cDFT) to predict transition energies of $\mathrm{Ce}^{3+}$ or $\mathrm{Eu}^{2+}$ doped phosphor compounds. $\frac{53155}{55}$ In these studies, authors applied the so-called constrained DFT methodology (cDFT) as commonly used in molecular simulations. $\frac{52}{2}$ In that context, we embarked on a tentative elucidation of the luminescence properties of Ti doped $m-\mathrm{ZrO}_{2}$ via DFT calculations.

Herein, we report a computational study to provide more clues on the origin of the whiteblue luminescence of $m-\mathrm{ZrO}_{2}$ :Ti. Our calculations strongly advocate that $\mathrm{Ti}_{\mathrm{Zr}}$ is at the origin of the white-blue emission in $m-\mathrm{ZrO}_{2}$ at $\approx 477 \mathrm{~nm}(2.6 \mathrm{eV})$. To do so, we combined cDFT to model excited state together with the estimation of defect formation enthalpies (DFEs) and charge transition levels (CTLs) of point defects. Also, we demonstrated that titanium center is stable at the oxidation state $+\mathrm{IV}$ even with the presence of oxygen vacancies. 


\section{${ }_{65}$ Methods}

\section{Ground and Excited States Modelling for the cDFT approach}

\section{Accurate Bulk Structure}

We performed first-principles simulations based on the Density Functional Theory (DFT) within the projector augmented wave (PAW) method, as implemented in the VASP software. $\stackrel{56}{58}$ Excited state simulations have been conducted using the PBE functional ${ }^{[59}$ with a cutoff energy set to $550 \mathrm{eV}$. Full geometry relaxation of the unitcell was performed considering a $4 \times 4 \times 4$ Monkhorst-Pack $k$-mesh (16 irreducible $k$-points). ${ }^{60}$ Atomic forces and total energy were minimized until threshold values of $1 \mathrm{meV} / \AA$ and $10^{-6} \mathrm{eV}$, respectively. Accurate energy calculations were carried out with a $6 \times 6 \times 6 \Gamma$-centered $k$-points sampling (80 irreducible $k$-points).

\section{Ground and Excited States}

A $2 \times 2 \times 2$ supercell was built in which the $V_{O}$ and $T i_{Z r}$ were evaluated. Structural relaxations were performed on all geometries for both GS (Ground State) and ES (Excited State), together with accurate energies determined with a smaller density $k$-mesh ( $\Gamma$ point only) to reduce the (already) heavy computational cost. We kept strong threshold values during the optimizations $\left(5 \mathrm{meV} / \AA\right.$ and $\left.10^{-6} \mathrm{eV}\right)$.

On these grounds, we computed the emission wavelengths using the $\Delta \mathrm{SCF}$ procedure as reported in Ref 53 55. Here, the emission energy expression is given by the formulae

$$
E_{e m}=E\left(A_{1}^{*}\right)-E\left(A_{1}\right)
$$

where $E\left(A_{1}^{*}\right)$ is the total energy of the relaxed excited state $\left(Q_{E S}\right.$ in Figure 1), and $E\left(A_{1}\right)$ is the total energy of the ground state enforcing the excited state geometry. The energy difference corresponds to the electronic vertical emission. 


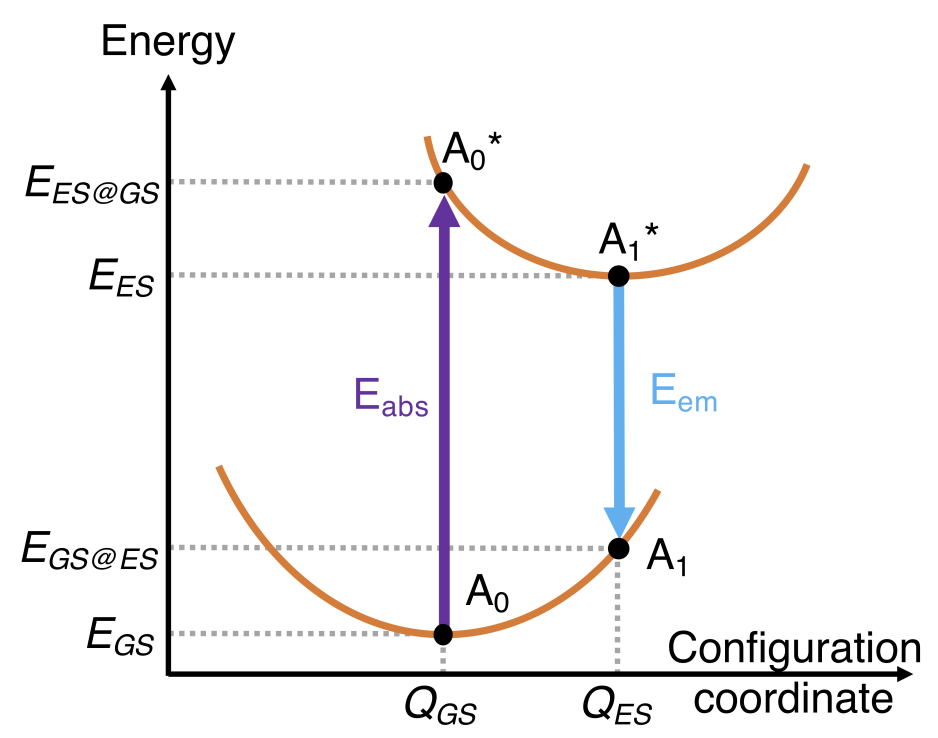

Figure 1: Schematic representation of the absorption and emission processes with respect to the configuration coordinate $Q$.

\section{Point Defects Modelling}

For point defect calculations, in order to reduce the computational time and after careful checks, the plane waves basis expansion was set with a cutoff energy of $500 \mathrm{eV}$. We considered the meta-GGA SCAN (Strongly Constrained and Appropriately Normed) approach to describe the exchange-correlation potential. $\stackrel{61}{6 u l l}$ geometry relaxations were done on the unit-cell until atomic forces were lower than $5 \mathrm{meV} / \AA$ and with a $12 \times 12 \times 12 \Gamma$-centered $k$-mesh (518 irreducible $k$-points).

Faulted structures with isolated (complex) point defects were built based on a $2 \times 2 \times 2$ $(3 \times 3 \times 3)$-supercell of the fully relaxed $\mathrm{ZrO}_{2}$ primitive unit cell. Atomic relaxations were conducted until forces on atoms are below $10 \mathrm{meV} / \AA$. A $4 \times 4 \times 4 \Gamma$-centered $k$-mesh (36 irreducible $k$-points) was used. For complex defects, geometry relaxations were done considering a $1 \times 1 \times 1 \Gamma$-centered $k$-mesh, and a $2 \times 2 \times 2 \Gamma$-centered $k$-mesh was used for accurate energy calculations.

Defect formation enthalpies were estimated using the supercell approach and assuming point defects are sufficiently diluted in it. In such a situation, interactions between periodic 
boundary images are minimized and the volume of the supercell does not suffer any changes. Thus, DFEs may be computed with the following formula:

$$
\Delta_{f} H^{D, q}\left(\mu_{E_{F}}\right)=\left(E_{D F T}^{D, q}-E_{D F T}^{h o s t}\right)+\sum_{i} n_{i} \mu_{i}+q\left(E_{V B M}^{h o s t}+\mu_{E_{F}}\right)+E_{c o r r}
$$

where $\Delta_{f} H^{D, q}$ is the DFE of a defect $D$ in a charge state $q, E_{D F T}^{D, q}$ is the DFT total energy of the faulted structure, $E_{D F T}^{\text {host }}$ is the DFT total energy of the host structure, $n_{i}$ is the number of atoms of the $i^{\text {th }}$ specie added $\left(n_{i}<0\right)$ or removed $\left(n_{i}>0\right)$ from the ideal material, $\mu_{i}$ is the chemical potential of the related species, $\mu_{E_{F}}$ is the Fermi level, $E_{V B M}^{\text {host }}$ corresponds to the valence band maximum (VBM) of the host material, and $E_{\text {corr }}$ is associated to various corrections of spurious effects (see SI for more details).

The charge transition levels $\epsilon\left(q / q^{\prime}\right)$ for probed defects were also calculated. CTLs correspond to the Fermi level position for which the two charge states $q$ and $q^{\prime}$ of a same point defect $D$ are involved in a thermodynamic equilibrium, i.e., both species are in equal amount. This quantity is expressed as:

$$
\epsilon\left(q / q^{\prime}\right)=\frac{\Delta_{f} H^{D, q}\left(\mu_{E_{F}}=0\right)-\Delta_{f} H^{D, q^{\prime}}\left(\mu_{E_{F}}=0\right)}{q^{\prime}-q}
$$

All defect post-treatments were performed using the development version of the PyDEF software.

\section{Results}

\section{Host structure}

The primitive cell of the $m-\mathrm{ZrO}_{2}$ phase is given in Figure 2. The structure crystallizes in the $P 2_{1} / c$ space group and contains three atoms symmetrically nonequivalent, all of them being positioned in a $4 e$ Wyckoff site. The first oxygen atom (hereafter labelled $\mathrm{O}(3)$ ) is located 
a)

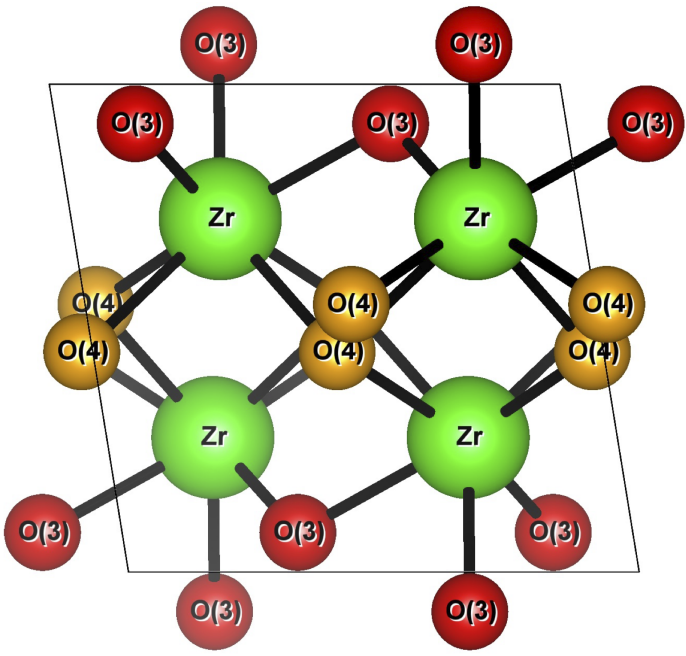

c)

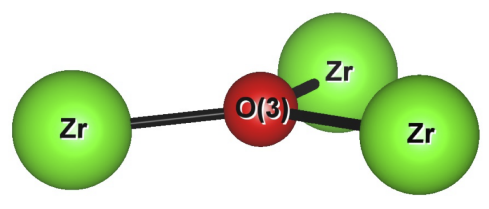

b)

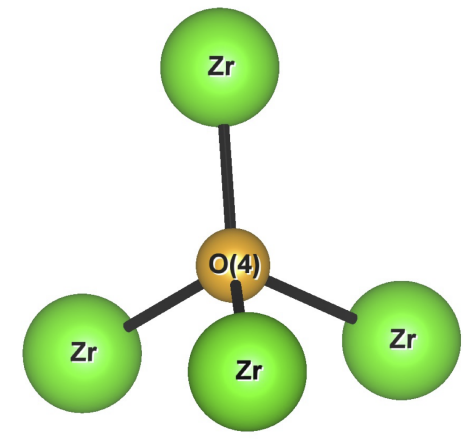

d)

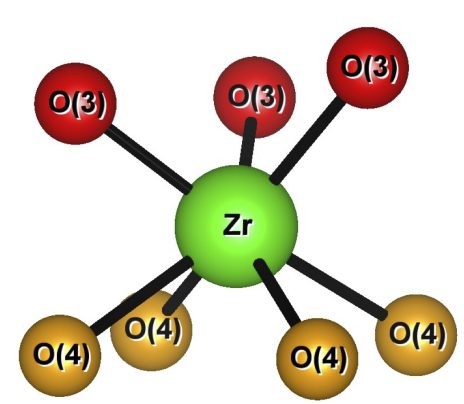

Figure 2: (a) View of the primitive cell of $m-\mathrm{ZrO}_{2}$ along the [001] crystallographic direction. $\mathrm{Zr}$ atoms are represented by green spheres. $\mathrm{O}(3)$ and $\mathrm{O}(4)$ species are distinguished by red and orange spheres, respectively. (b) $\mathrm{O}(4)$ tetragonal, (c) $\mathrm{O}(3)$ trigonal plane and (d) Zr 7-coordinated environments.

\section{Emission and Excited State Electronic Structures}

\section{Computed Electronic Emission}

Most of previous experimental studies attributed the origin of blue luminescence in zirconia to the presence of titanium. Following these conclusions, a doped system was built with the substitution of one zirconium by a titanium atom. The faulted structure was relaxed at both the GS and ES, followed by accurate energy calculations. Then the vertical electronic 
emission energy was computed following the protocol given in the computational section. Our simulated $\mathrm{Ti}^{3+}+\mathrm{O}^{-} \rightarrow \mathrm{Ti}^{4+}+\mathrm{O}^{2-}$ electronic emission $(\simeq 2.61 \mathrm{eV})$ is in outstanding agreement with the observed one $(\approx 2.6 \mathrm{eV}) . \frac{13115116}{}$ Therefore, with respect to the level of accuracy used herein, the luminescence measured at around $477 \mathrm{~nm}$ is very likely due to the presence of $\mathrm{Ti}^{4+}$ substituting $\mathrm{Zr}^{4+}$ cations. We now discuss in more details the structure and electronic structure for this doped material. The calculated bond lengths around the metal at both GS and ES are given in Table 1. As expected, there is a strong local rearrangement around the metal upon the excitation process. Indeed, the five short Ti-O distances (1.86 $\left.<d_{T i-O}<2.12 \AA\right)$ become larger $\left(2.02<d_{T i-O}<2.19 \AA\right)$ when going from the $A_{0}$ ground to the $A_{1}^{*}$ excited states, and the largest ones $\left(2.35<d_{T i-O}<2.43 \AA\right)$ at the ground state become shorter $\left(2.28<d_{T i-O}<2.32 \AA\right)$ at the excited state. In average, the Ti-O distances are $\approx 2 \%$ larger in the excited state than in the ground state. Finally, one must say that all the Ti-O(3)-type bonds $(\mathrm{O}(3)=\mathrm{O} 1, \mathrm{O} 2$ and $\mathrm{O} 3)$ are elongated when going from the ground to the excited state, while Ti-O(4)-type bonds gain in homogeneity with a mean value decreasing.

Table 1: (left) Ti environment. Ti, $\mathrm{O}(3)$ and $\mathrm{O}(4)$ atoms are depicted by blue, red and orange spheres, respectively. (right) Ti-O distances at both ground and excited states together with their respective variations $\Delta(r)$ (in $\AA)$.

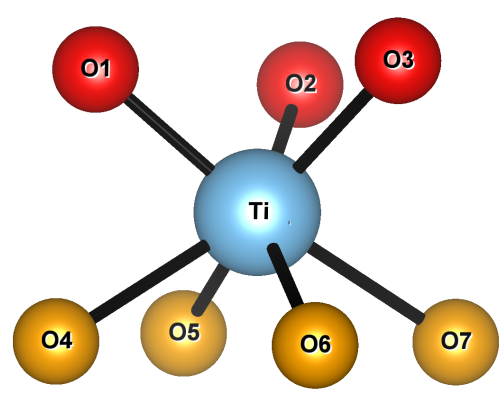

\begin{tabular}{cccc} 
Bond & $A_{0}$ & $A_{1}^{*}$ & $\Delta(r)$ \\
\hline $\mathrm{Ti}^{-} \mathrm{O}_{1}$ & 1.868 & 2.027 & 0.159 \\
$\mathrm{Ti}-\mathrm{O}_{2}$ & 2.032 & 2.065 & 0.033 \\
$\mathrm{Ti}-\mathrm{O}_{3}$ & 1.940 & 2.050 & 0.110 \\
$\mathrm{Ti}-\mathrm{O}_{4}$ & 2.355 & 2.311 & -0.044 \\
$\mathrm{Ti}_{5} \mathrm{O}_{5}$ & 2.113 & 2.188 & 0.075 \\
$\mathrm{Ti}_{6}$ & 2.118 & 2.185 & 0.067 \\
$\mathrm{Ti}^{-} \mathrm{O}_{7}$ & 2.427 & 2.281 & -0.146
\end{tabular}

The projected density of states (see Figure S1 in SI) of this compound evidences that, as expected, the valence band is built upon the oxygen atoms and the bottom of the conduction band is constituted by (mainly) titanium, the $d$-block of Zr being higher in energy than the $d$ block of Ti. We can therefore characterize the charge transfer occurring during the excitation 
process, which corresponds to a transfer from oxygen orbitals to titanium ones. We can also go further and assign the charge transfer occurring during the emission process by comparing the charge densities of the last occupied states at both $A_{1}^{*}(E S @ E S$, i.e., the electronic excited state at the excited state geometry) and $A_{1}$ (GS@ES, i.e., the electronic ground state at the excited state geometry) states represented in Figure 3. As one can see, for the $A_{1}^{*}$ state, the charge density is unambiguously located around the titanium site and presents a $d$ orbital-like shape. Concerning the $A_{1}$ state, the charge density is strongly delocalized over $\mathrm{O}(3)$ atoms, i.e., $\mathrm{O}$ atoms with a pseudo lone pair that contributes to the uppermost levels of the valence band (see Figure S2 in SI). Thus, this calculated emission at $\approx 2.6 \mathrm{eV}$ is clearly assigned to a Ti-3d $\rightarrow$ O- $2 p$ charge transfer, supporting a recent proposition based on experimental investigations. $\stackrel{24}{24}$

a)

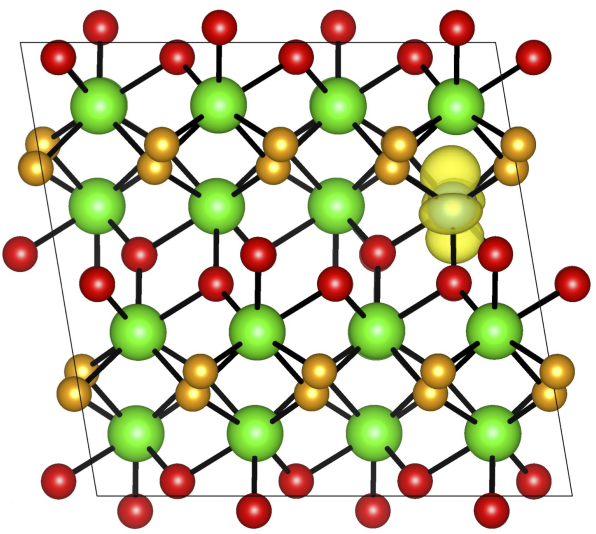

b)

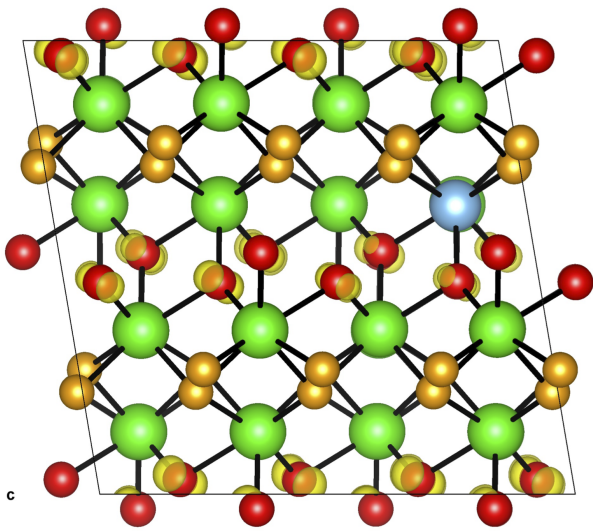

Figure 3: Projected charge densities on the last occupied electronic state at the (a) initial and (b) final step of the emission process within the Ti-doped $\mathrm{ZrO}_{2}$ system. $\mathrm{Zr}, \mathrm{Ti}, \mathrm{O}(3)$ and $\mathrm{O}(4)$ atoms are represented by green, blue, red and orange spheres, respectively.

In addition, our findings are in good agreement with different experimental works that commonly assign the broad blue luminescence band of titanium doped materials to the presence of $\mathrm{Ti}^{4+}$ ions and report that $\mathrm{Ti}^{3+}$ lead to emission at lower energies (red/orange/yellow). $.64[66$ More particularly, the emission band located at $490 \mathrm{~nm}(2.53 \mathrm{eV})$ in $\mathrm{MgAl}_{2} \mathrm{O}_{4}$ :Ti crystals was shown to be due to the presence of $\mathrm{Ti}^{4+}$ involved in a CT mechanism. ${ }^{64}$ Based on ESR measurements, an experimental study performed on Ti-doped low-silica calcium aluminosilicate 
glass (LSCAS) evidenced that visible luminescent bands at $640 \mathrm{~nm}(1.94 \mathrm{eV})$ and $480 \mathrm{~nm}$ $(2.58 \mathrm{eV})$ originate from $\mathrm{Ti}^{3+}\left(d-d\right.$ transition) ions and $\mathrm{Ti}^{4+}$, respectively. ${ }^{65} \mathrm{An}$ experimental study conducted on aluminophosphate glass and sapphire assigned the $840 \mathrm{~nm}(1.48 \mathrm{eV})$ and $747 \mathrm{~nm}(1.66 \mathrm{eV})$ luminescent bands to $\mathrm{Ti}^{3+}$ ions $\frac{\sqrt[6768]{6}}{T}$ Thus, on many different materials, the luminescence at about $2.5-3.0 \mathrm{eV}$ can be attributed to $\mathrm{Ti}^{4+}$ and not to $\mathrm{Ti}^{3+}$ ions in good agreement with our calculations on $\mathrm{Ti}$ doped $\mathrm{ZrO}_{2}$.

To go deeper in the analysis, we estimated defect formation enthalpies and the position of charge transition levels for intrinsic and extrinsic point defects. Such study turns out to be necessary to prove that $\mathrm{Ti}^{4+}$ are easily formed through zirconium substitution and the emission at about $2.60 \mathrm{eV}$ indubitably originates from a $\mathrm{Ti}^{3+} / \mathrm{O}^{2-}$ charge transfer.

\section{Investigation of point defects}

Here, we considered the SCAN functional to estimate defect formation enthalpies (DFEs) for intrinsic defects and Ti impurities. This functional was chosen since it is cost affordable, accurate for structure predictions and reliable for point defect properties as demonstrated by some of us. ${ }^{[35}$ The lattice parameters of the ideal $m-\mathrm{ZrO}_{2}$ unitcell were calculated at $a=5.146$ $\AA, b=5.226 \AA, c=5.315 \AA$, and $\beta=99.32^{\circ}$, close to the experimental values ( $a=5.14422(4)$ $\AA, b=5.20969(5) \AA, c=5.31120(5) \AA$, and $\left.\beta=99.220(1)^{\circ}\right) .69$ The band gap was estimated at $4.14 \mathrm{eV}$, while a HSE06 ${ }^{700}$ approach gave $5.28 \mathrm{eV}$ close to already reported $\mathrm{GW}_{0}{ }^{71}$ (5.34 $\mathrm{eV}), \operatorname{HSE}^{40}(5.22 \mathrm{eV})$ and $\operatorname{EELS}^{72]}(5.3 \mathrm{eV})$ data. For a HSE06@SCAN calculation (i.e., HSE06 band gap estimated on the fully optimized SCAN structure), we found $5.23 \mathrm{eV}$ in great agreement with the HSE06 value. Thus, in the following, we considered the SCAN approach for all first-principles calculations concerning point defects, and HSE06@SCAN correction was introduced for a better description of the band gap requested to access more accurate calculated DFEs.

DFE calculations were carried out on intrinsic defects of $m-\mathrm{ZrO}_{2}$, i.e., vacancies $\left(V_{O}\right.$ and $\left.V_{Z r}\right)$, interstitials $\left(Z r_{i}\right.$ and $O_{i}$, the initial position corresponds to the one labelled P1 
in Ref 73) and antisites $\left(Z r_{O}\right.$ and $\left.O_{Z r}\right)$ under oxygen-poor (titanium-rich) and oxygen-rich (titanium-poor) atmospheres. The computational study was extended to Ti doped $\mathrm{ZrO}_{2}$ with Ti located at the $\mathrm{Zr}$ site $\left(T i_{Z r}\right)$ and at the interstitial position $\left(T i_{i}\right)$.

In the experimental literature, zirconia samples intentionally doped by titanium have been widely prepared by heating manufactured $\mathrm{TiO}_{2}$ and $\mathrm{ZrO}_{2}$ powders mixed together and

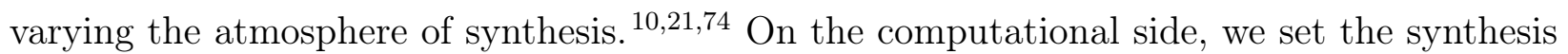
conditions by fixing the chemical potentials of the species in presence, such values being determined with the procedure already reported by some of us. ${ }^{33}$ Synthesis boundary conditions for the $m-\mathrm{ZrO}_{2}$ phase doped by titanium were determined on the basis of formation enthalpies of 12 competitive phases, leading to 8 extreme limits for the stability domain of zirconia (see Figure S3 and Table S2 in SI for more details). For the sake of clarity, we considered hereafter the extreme i) O-rich atmosphere (point A in Table S2, associated to the competition with $\mathrm{O}_{2}$ and $\mathrm{TiO}_{2}$ phases) and ii) O-poor atmosphere (point $\mathrm{H}$ in Table $\mathrm{S} 2$, associated to the competition with $\mathrm{Ti}_{3} \mathrm{O}$ and $\mathrm{Zr}$ phases). We mention that being under O-rich atmosphere will naturally prevent the formation of oxygen vacancies and titanium easily replaces zirconium. In O-poor conditions, an opposite behavior is expected. It is worth to underline that the increase of the oxygen vacancy content should inevitably lead to the formation of the tetragonal or cubic phases for $\mathrm{ZrO}_{2} \cdot{ }^{755}$ In that sense, this extreme O-poor synthesis condition constitutes a negative control for our point defect investigation targeting the $T i_{Z r}$ substitution.

DFEs are reported under each atmosphere for isolated point defects in Figure 4 . Computed defect concentrations are presented in Figure 4.

For intrinsic defects, charge transition levels were found in good agreement with those already reported in the literature estimated using hybrid functionals. ${ }^{42143}$ Briefly, we show that zirconium vacancies create both shallow and deep transition levels up to $1.43 \mathrm{eV}$ above the VBM with high DFEs under both atmospheres, unlikely to access for hole trapping/detrapping processes at room temperature. In the case of $V_{O}$ species, deep donor transition 
a)

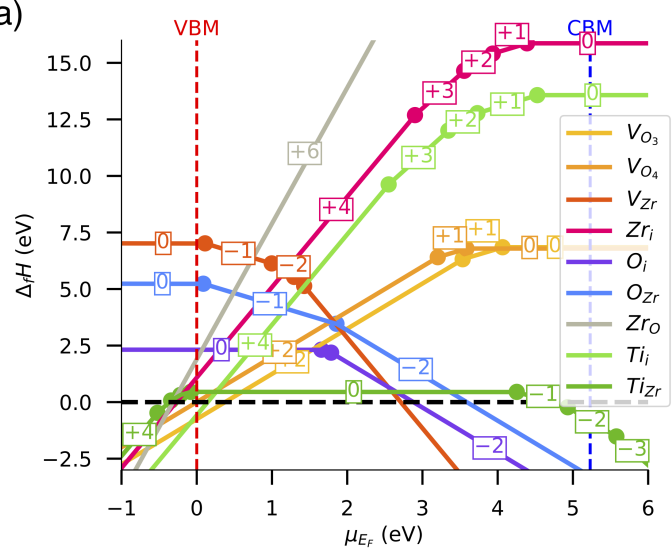

c)

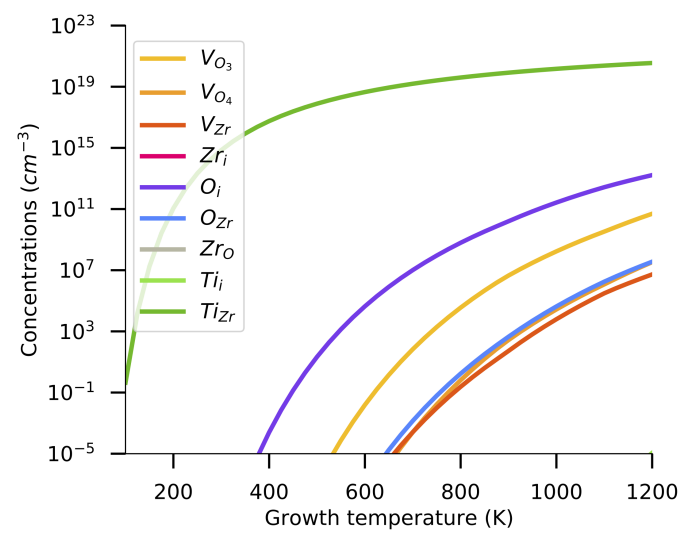

b)

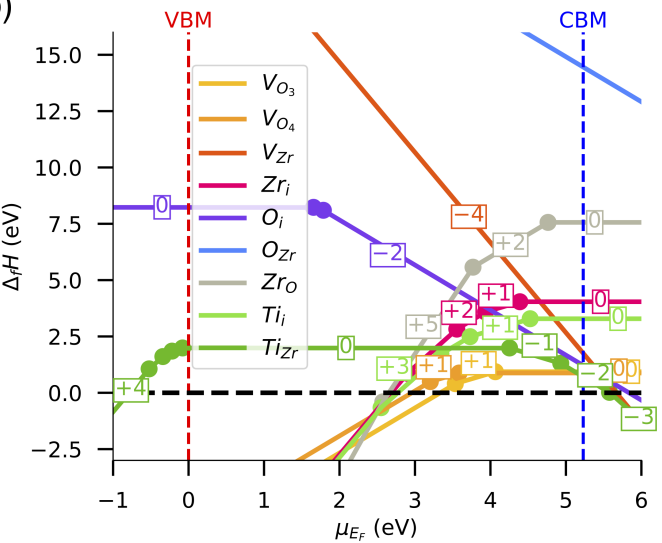

d)

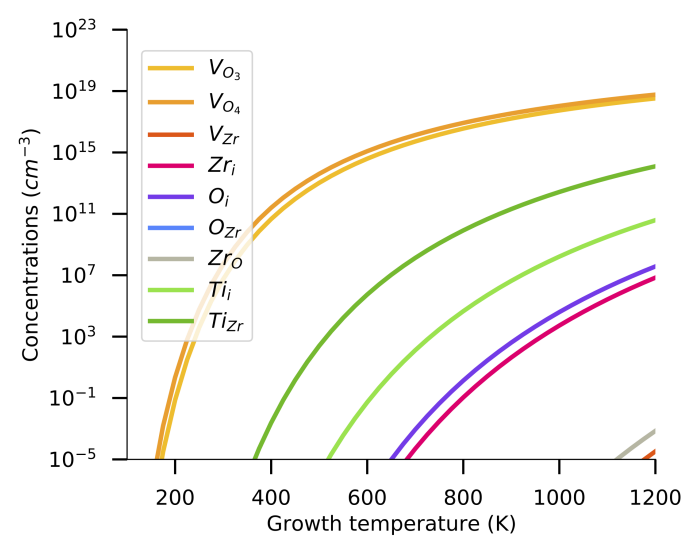

Figure 4: (a) Defect formation enthalpies vs. $\mu_{E_{F}}$ for O-rich (point A in Table S2) and (b) O-poor (point $\mathrm{H}$ in Table S2) synthesis conditions. (c) Defect concentrations vs. crystal growth temperature $T_{g r}$ for O-rich and (b) O-poor synthesis conditions.

levels are located between 1.19 and $2.05 \mathrm{eV}$ below the CBM, which drastically limits the direct thermal release of trapped electrons to the conduction band. For antisites, i.e., $Z r_{O}$ and $O_{Z r}$, the large computed DFEs evidence the impossibility to form such entities under both atmospheres. In the case of interstitials, deep transition levels are reported for both $\mathrm{Zr}$ and $\mathrm{O}$ species, but also with too high DFEs for potentially acting as charge carrier traps.

Concerning titanium interstitials, donor transition levels are found between 0.72 and 2.68 $\mathrm{eV}$ below the CBM with important DFEs whatever the synthesis conditions are. This let us suggest that such species are hardly created within $m-\mathrm{ZrO}_{2}$. In contrast, $T i_{Z r}$ entities present DFEs lower than $2 \mathrm{eV}$ for both synthesis conditions. Thus, titanium impurities 
prefer to substitute Zr atoms than occupy interstitial positions. Here, formal $\mathrm{Ti}^{4+} / \mathrm{Ti}^{3+}$ $(\epsilon(-1 / 0))$ and $\mathrm{Ti}^{3+} / \mathrm{Ti}^{2+}(\epsilon(-2 /-1))$ transition levels for $T i_{Z r}$ are lying within the gap and are respectively calculated at 0.98 and $0.30 \mathrm{eV}$ below the CBM.

More specifically to the O-rich limit, the dopability domain is set by $V_{O(3)}$ and $V_{Z r}$ intrinsic species for which DFEs are crossing the $\mu_{E_{F}}$ axis at 0.40 and $2.70 \mathrm{eV}$ above the VBM, respectively. The predominant defects are titanium impurities substituting zirconium at defect charge state $q=0$ within the whole region, as indicated by their low DFEs of $0.45 \mathrm{eV}$. Defect concentrations estimated for different growth temperatures confirm that this atmosphere of synthesis is ideal to stabilize $T i_{Z r}$ species. Typically, for $T_{g r}=1100 \mathrm{~K}$, we computed $\left[T i_{Z r}\right] \approx 10^{20} \mathrm{~cm}^{-3}$, the other point defects being found more than eight order of magnitude less concentrated. Also, we found $E_{F}^{g r}=1.80 \mathrm{eV}$, which reveals the preferential presence of formal $\mathrm{Ti}^{4+}$ during the synthesis. At working temperature $T_{w}=300 \mathrm{~K}$, the Fermi level moves to $E_{F}^{w}=0.45 \mathrm{eV}$ which emphasizes that titanium remains at the oxidation state + IV at room temperature.

In O-poor conditions, $V_{O(3)}$ still pins the $p$-type limit but this time at $1.90 \mathrm{eV}$ below the CBM. Under this atmosphere, oxygen vacancies exhibit the lowest DFEs, leading to $\left[V_{O(3)}\right]=1.5 \times 10^{18} \mathrm{~cm}^{-3}$ and $\left[V_{O(4)}\right]=2.7 \times 10^{18} \mathrm{~cm}^{-3}$ for $T_{g r}=1100 \mathrm{~K}$, while Ti species are significantly less concentrated $\left(\left[T i_{Z r}\right]=2.2 \times 10^{13} \mathrm{~cm}^{-3}\right.$ and $\left.\left[T i_{i}\right]=3.2 \times 10^{9} \mathrm{~cm}^{-3}\right)$. Here, we found $E_{F}^{g r}=4.07 \mathrm{eV}$, which indicates that $V_{O(3)}^{0}, V_{O(3)}^{+1}$ and $V_{O(4)}^{0}$ are strongly favoured during the synthesis. At $T_{w}=300 \mathrm{~K}$, only oxygen vacancy entities at charge states $q=0$ coexist due to the position of $E_{F}^{w}$ at $4.65 \mathrm{eV}$. In these conditions, $\mathrm{Ti}^{3+}$ cations at $\mathrm{Zr}$ sites are expected in much larger concentrations than $\mathrm{Ti}^{4+}, \epsilon(-1 / 0)$ transition level of $T i_{Z r}$ defects being located at $4.25 \mathrm{eV}$.

To sum up, the extreme synthesis conditions of choice for the stabilization of $T i_{Z r}$ species is an O-rich atmosphere (point A), which notably favours the existence of $\mathrm{Ti}^{4+}$ in place of $\mathrm{Zr}^{4+}$. Thus, the luminescent properties in $m-\mathrm{ZrO}_{2}$ are particularly favoured for such synthesis conditions, except if the concentration of Ti impurities is too large and leads to concentration 
quenching phenomena. In contrast, an extreme reduced atmosphere (point $\mathrm{H}$ ) will tend to promote the formation of oxygen vacancies, while titanium impurities appear significantly less concentrated with an oxydation state lower than + IV. For this last case, experimentally, oxygen vacancies are so prompt to be formed that they may irresistibly induce a phase transition to the tetragonal or cubic forms, ${ }^{75}$ (77 (usually stabilized with the help of $\mathrm{Y}^{3+}$ ). This clearly means that calculations on $m-\mathrm{ZrO}_{2}$ in O-poor conditions have to be regarded as an unrealistic solution $\frac{\sqrt{75} / 77}{76}$ that nevertheless shed light on the reactivity of the system to a stimulus, the deprivation of oxygen.

Experimental analyzes pointed that $V_{O}$ entities may coexist with titanium impurities and could impact the photoluminescence intensity. ${ }^{[15116}$ Regarding the luminescent properties, the most commonly adopted mechanism $\frac{12141}{1}$ which involves intra-site $d$ - $d$ electronic transitions at $\mathrm{Ti}^{3+}$ explains the changes in the photoluminescence intensity by the reduction of $\mathrm{Ti}^{4+}$ species due to the presence of neighboring $V_{O}$ species. This supposition is notably weakened by the absence of $\mathrm{Ti}^{3+}$ species into ESR spectra. $\frac{16}{16}$

From our theoretical investigations on point defects, we demonstrated that isolated $\mathrm{Ti}^{4+}$ are preferred to $\mathrm{Ti}^{3+}$ species under O-rich synthesis conditions, and are not supposed to be formed under O-poor conditions. Obviously, such extreme synthesis conditions might be not comparable with realistic (intermediate) atmospheres and their study would require more computational efforts. To go beyond this first attempt, we extended the point defect calculations to intermediate atmosphere limits located at the frontier of the $m-\mathrm{ZrO}_{2}$ stability domain. For fixed growth and room temperatures respectively at $T_{g r}=1100 \mathrm{~K}$ and $T_{w}=300$ $\mathrm{K}$, we followed the evolution of the charge state for $T i_{Z r}$ species for different atmospheres of synthesis.

For O-rich atmospheres (i.e., high $\Delta \mu_{O}$ values), we found that $\mathrm{Ti}^{4+}$ species are preferentially present within $m-\mathrm{ZrO}_{2}$, as observed in the extreme case at the A point $\left(\Delta \mu_{O}=0\right.$ $\mathrm{eV})$. By reducing more and more the atmosphere of synthesis (i.e., by decreasing $\Delta \mu_{O}$ ), the concentration of oxygen vacancies increases and the charge balance is displaced to stabilize 


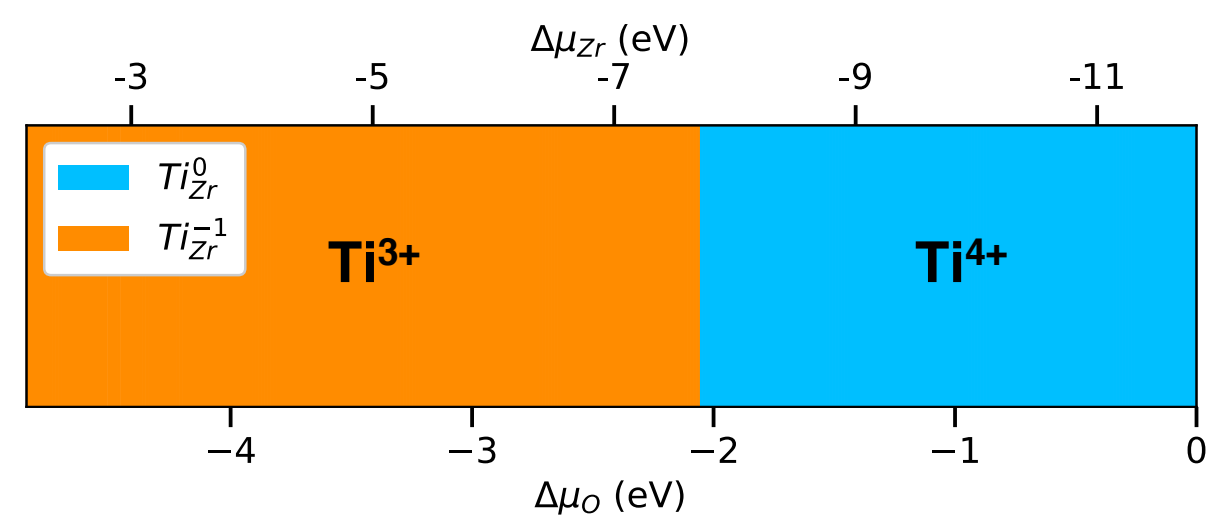

Figure 5: Nature of $T i_{Z r}$ species in $m-\mathrm{ZrO}_{2}$ as a function of synthesis conditions. These atmospheres correspond to the frontier of the $m-\mathrm{ZrO}_{2}$ stability domain between the $\mathrm{A}$ and E points (see Figure S3 and Table S2 in SI). The related chemical potential deviations (in $\mathrm{eV}$ ) of oxygen $\left(\Delta \mu_{O}\right)$ and zirconium $\left(\Delta \mu_{Z r}\right)$ are only reported for clarity. Results were obtained considering the growth and room temperatures arbitrarily set at 1100 and $300 \mathrm{~K}$, respectively.

$\mathrm{Ti}^{3+}$ species (see Figure 5). Here, the change in oxidation state for Ti from $+\mathrm{IV}$ to $+\mathrm{III}$ is observed at $\Delta \mu_{O}=-2.05 \mathrm{eV}\left(\mu_{O}=-8.07 \mathrm{eV}\right)$. While $\Delta \mu_{O}$ values are decreasing, $\Delta \mu_{Z r}$ is enhanced due to the constraint imposed by $\Delta H_{f}\left(\mathrm{ZrO}_{2}\right)=\Delta \mu_{\mathrm{Zr}}+2 \Delta \mu_{O}$. The synthesis conditions become more and more $\mathrm{Zr}$-rich which tends to disfavour the substitution of $\mathrm{Zr}$ by Ti, favour the formation of oxygen vacancies and thus the transition to cubic or tetragonal phases. In that sense, the point $\mathrm{E}\left(\Delta \mu_{O}=-4.85 \mathrm{eV}\right)$ constitutes a reasonable limit for our analysis to form $T i_{Z r}$ defects within monoclinic zirconia.

Under O-poor conditions, in a more realistic picture, both species, $T i_{Z r}$ and $V_{O}$, may coexist at (slightly) different ratios vs. the oxygen atmospheres. Because the clustering of point defects might not be avoided, we attempted to estimate first accessible transition levels for $T i_{Z r}-V_{O}$ based complex entities by considering a $3 \times 3 \times 3$ supercell of 324 atoms. Three combinations were considered: coexistence of $V_{O}$ with i) one Ti impurity (labelled $\left.\left(T i_{Z r}-V_{O}\right)\right)$, ii) two Ti (labelled $\left.\left(2 T i_{Z r}-V_{O}\right)\right)$, and iii) one Ti plus another isolated Ti (labelled $\left.\left(T i_{Z r}-V_{O}\right)+T i_{Z r}\right)$. Corresponding transition levels are presented in Table 2 and compared to levels of isolated defects in Figure 6 .

Here, the calculated transition levels $\epsilon(0 /+1)$ appear slightly shifted toward the middle 
Table 2: Position of the $\epsilon(+1 / 0)$ transition level (in $\mathrm{eV}$ ) within the band gap for complex defects under $\mathrm{O}$-poor synthesis conditions

\begin{tabular}{lc} 
Defect species & $\epsilon(+1 / 0)$ \\
\hline$\left(T i_{Z r}-V_{O(3)}\right)$ & 3.88 \\
$\left(T i_{Z r}-V_{O(4)}\right)$ & 3.58 \\
$\left(2 T i_{Z r}-V_{O(3)}\right)$ & 3.86 \\
$\left(2 T i_{Z r}-V_{O(4)}\right)$ & 3.62 \\
$\left(T i_{Z r}-V_{O(3)}\right)+T i_{Z r}$ & 3.89 \\
$\left(T i_{Z r}-V_{O(4)}\right)+T i_{Z r}$ & 3.59
\end{tabular}

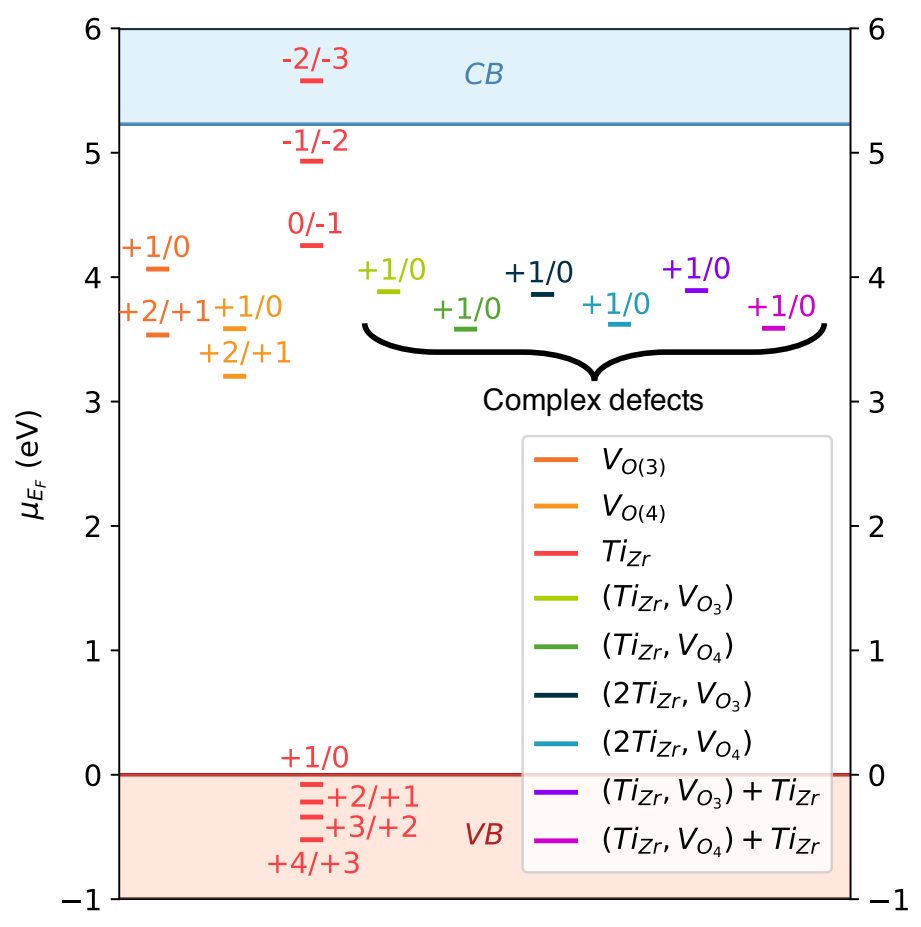

Figure 6: Charge transition levels for point defects of interest, i.e., oxygen vacancies, zirconium substituted by titanium and complex defects.

of the gap, moving below previous $E_{F}^{g r}$ values. The investigations on the electronic properties reveal null spin densities for all complex defects at charge state $q=0$, confirming the stabilization of $\mathrm{Ti}^{4+}$ species after doping. 


\section{Discussions}

We undertook a computational investigation to provide new insights concerning the blue emission process of $m-\mathrm{ZrO}_{2}$, for which several investigations proposed different mechanisms. Based on conclusions from the $\triangle \mathrm{SCF}$ calculations, the origin of luminescence at $\approx 2.6 \mathrm{eV}$ is explained by the charge transfer (CT) from Ti impurities substituting zirconium, in the lines of previous works. ${ }^{24}$ Indeed, we demonstrated the de-excitation from Ti electronic states is characterized by an energy transition of $2.61 \mathrm{eV}$.

Other arguments can be brought to support the fact that the presence of $\mathrm{Ti}^{4+}$ ions are responsible for the blue band. For instance, transition metal oxides containing $n d^{0}$ ions such as titanates (or vanadates) are known to present such CT luminescence, associated with an intense absorption band in the UV region, a high Stokes shift $(\approx 1.5-2.5 \mathrm{eV})$ and a very broad $(\approx 0.5-0.6 \mathrm{eV})$ emission band ${ }^{79}$ These particular features have been reported experimentally for $m-\mathrm{ZrO}_{2} \cdot \frac{15 \mid 16}{16}$

To argue that the blue luminescence is due to the presence of $\mathrm{Ti}^{4+}$ ions and not to intrasite $d$ - $d$ transitions for $\mathrm{Ti}^{3+}$ in bulk $m-\mathrm{ZrO}_{2}$, one can also consider the result from pDOS represented in Figure S1 (in SI). Titanium $d$ states that appears inside the gap just below the conduction band are separated in an energy range smaller than $2.6 \mathrm{eV}$. A large splitting of $d$ orbitals would be required to allow $d$ - $d$ transition and provide blue light.

In the lines of these studies, our point defect calculations demonstrated that $\mathrm{Ti}^{4+}$ species are preferentially formed for most of the synthesis conditions, especially under O-rich atmospheres. In the extreme O-rich limit, the defect formation enthalpies for $T i_{Z r}$ are so small that Ti doping can be easily done and thus increase the photoluminescence intensity. Nevertheless, quenching phenomena have been reported when the concentration in titanium impurites increases above $\approx 1 \mathrm{wt} \%, \frac{16}{16}$ and one may wonder if intermediate situations are preferable to avoid such a situation.

It is worth to note that different experimental studies argue that the blue luminescence might find its origin from the presence of $\mathrm{Ti}^{3+}$ ions inside $\mathrm{ZrO}_{2}, \frac{1380}{180}$ notably created by the 
coexistence with lattice defects. ${ }^{16}$ More specifically, Wang et al. observed that the intensity of the blue band rises with the annealing temperature. The authors proposed that the oxygen vacancy content is enhanced accordingly, which reduces titanium in $\mathrm{Ti}^{3+}$ due to the charge compensation. This assumption can be rebutted by the fact that annealing has been done under air which could bring oxide ions in the material and thus oxide ions modifying $\mathrm{Ti}^{3+}$ in $\mathrm{Ti}^{4+}$.

At the end, one may notice that the transition levels of $T i_{Z r}$ defects and $\left(T i_{Z r}, V_{O}\right)$ complexes are separated by about $0.4-0.7 \mathrm{eV}$ according to the nature of the oxygen vacancies $\left(V_{O(3)}\right.$ or $\left.V_{O(4)}\right)$. Consequently, to account for the long lasting luminescence observed at $\approx 2.6$ $\mathrm{eV}$ for $\mathrm{ZrO}_{2}: \mathrm{Ti}$ compounds after excitation at $\approx 2.6 \mathrm{eV}, \underline{16}$ it is quite possible that electron resulting from an $\mathrm{Zr}^{4+}+\mathrm{O}^{2-} \rightarrow \mathrm{Zr}^{3+}+\mathrm{O}^{-}\left(\right.$or $\left.\mathrm{Ti}^{4+}+\mathrm{O}^{2-} \rightarrow \mathrm{Ti}^{3+}+\mathrm{O}^{-}\right)$energy transfer is trapped by an oxygen vacancy located nearby $T i_{Z r}$ substituted site. This electron might be subsequently released at room temperature via a thermal assisted process (the ideal experimental activation energy is estimated around $0.6 \mathrm{eV}), 81$ with the de-excitation at a $T i_{Z r}$ site according to the $\mathrm{CT} \mathrm{Ti}^{3+}+\mathrm{O}^{-} \rightarrow \mathrm{Ti}^{4+}+\mathrm{O}^{2-}$. Thus, complex defects might be at the origin of luminescence properties in $m-\mathrm{ZrO}_{2}$ but also of the long persistent luminescence reported in $m-\mathrm{ZrO}_{2} \cdot \frac{15}{15}$

\section{Conclusion}

We reported a computational study to determine the origin of the blue emission band of the monoclinic zirconia phase. Based on the $\triangle \mathrm{SCF}$ method for the first time on such material, we clearly demonstrate that the luminescence arises from a charge transfer between titanium substituting Zr atoms and oxygen atoms from the lattice, and remove the uncertainty concerning oxygen vacancies. To confirm the easy Ti doping, defect formation enthalpies were estimated for intrinsic and extrinsic species. We notably evidenced that $\mathrm{Ti}^{4+}$ are easily created within Zr sites. 


\section{Acknowledgement}

This work was performed using HPC resources from GENCI-TGCC (Grant 2020-A0080911491) and CCIPL (Centre de Calculs Intensifs des Pays de la Loire). CL thanks the CNRS and "Région Pays de la Loire" to support the "CLIC" project. The authors thanks the French National Research Agency (ANR) for its financial support (ANR-18-CE08-0012 PERSIST project) and the CNRS. Crystal structures were represented using the VESTA software. ${ }^{82}$

\section{Supporting Information Available}

Details on the ground state structure used for excited state calculations, the unitcell structure considered for point defect simulations, stability phase diagram of Ti-doped $\mathrm{ZrO}_{2}$, defect formation enthalpies, concentrations of point defects

\section{References}

(1) Loebs, V. A.; Haas, T. W.; Solomon, J. S. Characterization of the initial growth of Si on cubic stabilized zirconia. Journal of Vacuum Science \& Technology A 1983, 1, $596-599$.

(2) Hobein, B.; Tietz, F.; Stöver, D.; Čekada, M.; Panjan, P. DC Sputtering of yttriastabilised zirconia films for solid oxide fuel cell applications. Journal of the European Ceramic Society 2001, 21, 1843-1846.

(3) Rätzer-Scheibe, H. J.; Schulz, U.; Krell, T. The effect of coating thickness on the thermal conductivity of EB-PVD PYSZ thermal barrier coatings. Surface and Coatings Technology 2006, 200, 5636-5644.

(4) Ivers-Tiffée, E.; Härdtl, K. H.; Menesklou, W.; Riegel, J. Principles of solid state oxygen sensors for lean combustion gas control. Electrochimica Acta 2001, 47, 807-814. 
(5) Gribelyuk, M. A.; Callegari, A.; Gusev, E. P.; Copel, M.; Buchanan, D. A. Interface reactions in $\mathrm{ZrO}_{2}$ based gate dielectric stacks. Journal of Applied Physics 2002, 92, $1232-1237$.

(6) Kauppi, E. I.; Honkala, K.; Krause, A. O. I.; Kanervo, J. M.; Lefferts, L. $\mathrm{ZrO}_{2}$ Acting as a Redox Catalyst. Topics in Catalysis 2016, 59, 823-832.

(7) Sarver, J. F. Preparation and Luminescent Properties of Ti-Activated Zirconia. Journal of The Electrochemical Society 1966, 113, 124.

(8) Phatak, G. M.; Gangadharan, K.; Pal, H.; Mittal, J. P. Luminescence properties of Tidoped gem-grade zirconia powders. Bulletin of Materials Science 1994, 17, 163-169.

(9) Petrik, N. G.; Taylor, D. P.; Orlando, T. M. Laser-stimulated luminescence of yttriastabilized cubic zirconia crystals. Journal of Applied Physics 1999, 85, 6770-6776.

(10) Cong, Y.; Li, B.; Lei, B.; Li, W. Long lasting phosphorescent properties of Ti doped $\mathrm{ZrO}_{2}$. Journal of Luminescence 2007, 126, 822-826.

(11) Cong, Y.; Li, B.; Yue, S.; Fan, D.; Wang, X.-j. Effect of Oxygen Vacancy on Phase Transition and Photoluminescence Properties of Nanocrystalline Zirconia Synthesized by the One-Pot Reaction. The Journal of Physical Chemistry C 2009, 113, 1397413978.

(12) Carvalho, J. M.; Rodrigues, L. C. V.; Hölsä, J.; Lastusaari, M.; Nunes, L. A. O.; Felinto, M. C. F. C.; Malta, O. L.; Brito, H. F. Influence of titanium and lutetium on the persistent luminescence of $\mathrm{ZrO}_{2}$. Optical Materials Express 2012, 2, 331-340.

(13) Wang, Z.; Zhang, J.; Zheng, G.; Liu, Y.; Zhao, Y. The unusual variations of photoluminescence and afterglow properties in monoclinic $\mathrm{ZrO}_{2}$ by annealing. Journal of Luminescence 2012, 132, 2817-2821. 
(14) Nikiforov, S. V.; Kortov, V. S.; Kazantseva, M. G.; Petrovykh, K. A. Luminescent properties of monoclinic zirconium oxide. Journal of Luminescence 2015, 166, 111116.

(15) Kiisk, V.; Puust, L.; Utt, K.; Maaroos, A.; Mändar, H.; Viviani, E.; Piccinelli, F.; Saar, R.; Joost, U.; Sildos, I. Photo-, thermo- and optically stimulated luminescence of monoclinic zirconia. Journal of Luminescence 2016, 174, 49-55.

(16) Nikiforov, S. V.; Menshenina, A. A.; Konev, S. F. The influence of intrinsic and impurity defects on the luminescent properties of zirconia. Journal of Luminescence 2019, 212, 219-226.

(17) Sawamura, K.; Iwasaki, K.; Nakanishi, T.; Iwakura, F.; Nakajima, Y.; Katsumata, K.-i.; Yasumori, A. Persistent luminescence properties of monoclinic luminescent zirconium oxide annealed under different oxygen partial pressures. Journal of the Ceramic Society of Japan 2020, 128, 175-180.

(18) Smits, K.; Grigorjeva, L.; Millers, D.; Sarakovskis, A.; Grabis, J.; Lojkowski, W. Intrinsic defect related luminescence in $\mathrm{ZrO}_{2}$. Journal of Luminescence 2011, 131, 2058-2062.

(19) Perevalov, T. V.; Gulyaev, D. V.; Aliev, V. S.; Zhuravlev, K. S.; Gritsenko, V. A.; Yelisseyev, A. P. The origin of $2.7 \mathrm{eV}$ blue luminescence band in zirconium oxide. Journal of Applied Physics 2014, 116, 244109.

(20) Guo, R.; Liu, T.; Lu, Y.; Li, Q.; Jiao, X.; Xu, X. First-principles study on the optical spectra of $\mathrm{ZrO}_{2}$ crystal with oxygen vacancy. International Journal of Modern Physics B 2019, 33, 1950372.

(21) Nakayama, S.; Sakamoto, M. Fluorescence property of $\mathrm{ZrO}_{2}$ :Ti phosphor and its enhancement in fluorescent intensity by adding phosphorus. Journal of Materials Research and Technology 2016, 5, 289-292. 
(22) Livraghi, S.; Olivero, F.; Paganini, M. C.; Giamello, E. Titanium Ions Dispersed into the $\mathrm{ZrO}_{2}$ Matrix: Spectroscopic Properties and Photoinduced Electron Transfer. The Journal of Physical Chemistry C 2010, 114, 18553-18558.

(23) Harrison, D. E.; Melamed, N. T.; Subbarao, E. C. A New Family of Self-Activated Phosphors. Journal of The Electrochemical Society 1963, 110, 23.

(24) Pan, G.-H.; Zhang, L.; Wu, H.; Qu, X.; Wu, H.; Hao, Z.; Zhang, L.; Zhang, X.; Zhang, J. On the luminescence of $\mathrm{Ti}^{4+}$ and $\mathrm{Eu}^{3+}$ in monoclinic $\mathrm{ZrO}_{2}$ : high performance optical thermometry derived from energy transfer. Journal of Materials Chemistry C 2020, 8, $4518-4533$.

(25) Lany, S.; Zunger, A. Assessment of correction methods for the band-gap problem and for finite-size effects in supercell defect calculations: Case studies for $\mathrm{ZnO}$ and GaAs. Physical Review B 2008, 78, 235104.

(26) Lany, S.; Zunger, A. Accurate prediction of defect properties in density functional supercell calculations. Modelling and Simulation in Materials Science and Engineering 2009, 17, 084002.

(27) Komsa, H.-P.; Rantala, T. T.; Pasquarello, A. Finite-size supercell correction schemes for charged defect calculations. Physical Review B 2012, 86, 045112.

(28) Freysoldt, C.; Grabowski, B.; Hickel, T.; Neugebauer, J.; Kresse, G.; Janotti, A.; Van de Walle, C. G. First-principles calculations for point defects in solids. Reviews of Modern Physics 2014, 86, 253-305.

(29) Park, J. S.; Kim, S.; Xie, Z.; Walsh, A. Point defect engineering in thin-film solar cells. Nature Reviews Materials 2018, 3, 194-210.

(30) Stoliaroff, A.; Barreau, N.; Jobic, S.; Latouche, C. $\beta-\operatorname{In}_{2} \mathrm{~S}_{3}$ for photovoltaic devices: 
investigation of the native point defects with ab initio first-principle calculations. Theoretical Chemistry Accounts 2018, 137, 102.

(31) Stoliaroff, A.; Jobic, S.; Latouche, C. Optoelectronic Properties of $\mathrm{TiS}_{2}$ : A Never Ended Story Tackled by Density Functional Theory and Many-Body Methods. Inorganic Chemistry 2019, 58, 1949-1957.

(32) Stoliaroff, A.; Latouche, C.; Jobic, S. Versatile electrical behavior of 1T-TiS 2 elucidated from a theoretical study. Physical Review B 2019, 99, 165122.

(33) Stoliaroff, A.; Jobic, S.; Latouche, C. New insights into the determination of maximum chemical potentials to account for alkali doping in $\beta-\operatorname{In}_{2} \mathrm{~S}_{3}$ by ab initio calculations. Computational Materials Science 2019, 168, 221-228.

(34) Stoliaroff, A.; Lecomte, A.; Rubel, O.; Jobic, S.; Zhang, X.; Latouche, C.; Rocquefelte, X. Deciphering the Role of Key Defects in $\mathrm{Sb}_{2} \mathrm{Se}_{3}$, a Promising Candidate for Chalcogenide-Based Solar Cells. ACS Applied Energy Materials 2020, 3, 2496-2509.

(35) Lafargue-Dit-Hauret, W.; Latouche, C.; Jobic, S. Ab Initio Prediction of the Redox Potentials of 3d Transition Metals Embedded in a Semiconducting Host Lattice. The Journal of Physical Chemistry C 2021, 125, 4267-4276.

(36) Foster, A. S.; Sulimov, V. B.; Lopez Gejo, F.; Shluger, A. L.; Nieminen, R. M. Structure and electrical levels of point defects in monoclinic zirconia. Physical Review B 2001, $64,224108$.

(37) Foster, A. S.; Sulimov, V. B.; Lopez Gejo, F.; Shluger, A. L.; Nieminen, R. M. Modelling of point defects in monoclinic zirconia. Journal of Non-Crystalline Solids 2002, 303, $101-107$.

(38) Zheng, J. X.; Ceder, G.; Maxisch, T.; Chim, W. K.; Choi, W. K. First-principles study of native point defects in hafnia and zirconia. Physical Review B 2007, 75, 104112. 
(39) Århammar, C.; Moysés Araújo, C.; Ahuja, R. Energetics of Al doping and intrinsic defects in monoclinic and cubic zirconia: First-principles calculations. Physical Review B 2009, 80, 115208.

(40) Lyons, J. L.; Janotti, A.; Van de Walle, C. G. The role of oxygen-related defects and hydrogen impurities in $\mathrm{HfO}_{2}$ and $\mathrm{ZrO}_{2}$. Microelectronic Engineering 2011, 88, 14521456.

(41) Zhao, S.; Xue, J.; Wang, Y.; Yan, S. Study on the effect of pressure on the properties of intrinsic point defects in monoclinic zirconia: Ab initio calculations. Journal of Applied Physics 2012, 111, 043514.

(42) Van de Walle, C. G.; Choi, M.; Weber, J. R.; Lyons, J. L.; Janotti, A. Defects at Ge/oxide and III-V/oxide interfaces. Microelectronic Engineering 2013, 109, 211-215.

(43) Shi, L. B.; Wang, Y. P.; Li, M. B. Native defect formation and migration in monoclinic zirconium dioxide. Materials Science in Semiconductor Processing 2014, 27, 586-592.

(44) Perevalov, T. V. Simulation of the Atomic and Electronic Structure of Oxygen Vacancies and Polyvacancies in $\mathrm{ZrO}_{2}$. Physics of the Solid State 2018, 60, 423-427.

(45) Jacquemin, D.; Perpète, E. A.; Ciofini, I.; Adamo, C. Accurate Simulation of Optical Properties in Dyes. Accounts of Chemical Research 2009, 42, 326-334.

(46) Jacquemin, D.; Mennucci, B.; Adamo, C. Excited-state calculations with TD-DFT: from benchmarks to simulations in complex environments. Physical Chemistry Chemical Physics 2011, 13, 16987-16998.

(47) Barone, V.; Baiardi, A.; Biczysko, M.; Bloino, J.; Cappelli, C.; Lipparini, F. Implementation and validation of a multi-purpose virtual spectrometer for large systems in complex environments. Physical Chemistry Chemical Physics 2012, 14, 12404-12422. 
(48) Adamo, C.; Jacquemin, D. The calculations of excited-state properties with TimeDependent Density Functional Theory. Chemical Society Reviews 2013, 42, 845-856.

(49) Baiardi, A.; Bloino, J.; Barone, V. General Time Dependent Approach to Vibronic Spectroscopy Including Franck-Condon, Herzberg-Teller, and Duschinsky Effects. Journal of Chemical Theory and Computation 2013, 9, 4097-4115.

(50) Vazart, F.; Latouche, C.; Bloino, J.; Barone, V. Vibronic Coupling Investigation to Compute Phosphorescence Spectra of Pt(II) Complexes. Inorganic Chemistry 2015, $54,5588-5595$.

(51) Bloino, J.; Baiardi, A.; Biczysko, M. Aiming at an accurate prediction of vibrational and electronic spectra for medium-to-large molecules: An overview. International Journal of Quantum Chemistry 2016, 116, 1543-1574.

(52) Massuyeau, F.; Faulques, E.; Latouche, C. New Insights To Simulate the Luminescence Properties of Pt(II) Complexes Using Quantum Calculations. Journal of Chemical Theory and Computation 2017, 13, 1748-1755.

(53) Canning, A.; Chaudhry, A.; Boutchko, R.; Grønbech-Jensen, N. First-principles study of luminescence in Ce-doped inorganic scintillators. Physical Review B 2011, 83, 125115.

(54) Jia, Y.; Miglio, A.; Poncé, S.; Gonze, X.; Mikami, M. First-principles study of Ce ${ }^{3+}$ doped lanthanum silicate nitride phosphors: Neutral excitation, Stokes shift, and luminescent center identification. Physical Review B 2016, 93, 155111.

(55) Jia, Y.; Miglio, A.; Poncé, S.; Mikami, M.; Gonze, X. First-principles study of the luminescence of $\mathrm{Eu}^{2+}$-doped phosphors. Physical Review B 2017, 96, 125132.

(56) Kresse, G.; Furthmüller, J. Efficiency of ab-initio total energy calculations for metals 
and semiconductors using a plane-wave basis set. Computational Materials Science 1996, 6, 15-50.

(57) Kresse, G.; Furthmüller, J. Efficient iterative schemes for ab initio total-energy calculations using a plane-wave basis set. Physical Review B 1996, 54, 11169-11186.

(58) Kresse, G.; Joubert, D. From ultrasoft pseudopotentials to the projector augmentedwave method. Physical Review B 1999, 59, 1758-1775.

(59) Perdew, J. P.; Burke, K.; Ernzerhof, M. Generalized Gradient Approximation Made Simple. Physical Review Letters 1996, 77, 3865-3868.

(60) Monkhorst, H. J.; Pack, J. D. Special points for Brillouin-zone integrations. Physical review $B$ 1976, 13, 5188 .

(61) Sun, J.; Ruzsinszky, A.; Perdew, J. Strongly Constrained and Appropriately Normed Semilocal Density Functional. Physical Review Letters 2015, 115, 036402.

(62) Péan, E.; Vidal, J.; Jobic, S.; Latouche, C. Presentation of the PyDEF post-treatment Python software to compute publishable charts for defect energy formation. Chemical Physics Letters 2017, 671, 124-130.

(63) Stoliaroff, A.; Jobic, S.; Latouche, C. PyDEF 2.0: An Easy to Use Post-treatment Software for Publishable Charts Featuring a Graphical User Interface. Journal of Computational Chemistry 2018, 39, 2251-2261.

(64) Sato, T.; Shirai, M.; Tanaka, K.; Kawabe, Y.; Hanamura, E. Strong blue emission from Ti-doped $\mathrm{MgAl}_{2} \mathrm{O}_{4}$ crystals. Journal of luminescence 2005, 114, 155-161.

(65) Andrade, L.; Lima, S.; Novatski, A.; Neto, A.; Bento, A.; Baesso, M.; Gandra, F.; Guyot, Y.; Boulon, G. Spectroscopic assignments of $\mathrm{Ti}^{3+}$ and $\mathrm{Ti}^{4+}$ in titanium-doped $\mathrm{OH}^{-}$free low-silica calcium aluminosilicate glass and role of structural defects on the 
observed long lifetime and high fluorescence of $\mathrm{Ti}^{3+}$ ions. Physical Review B 2008, 78, 224202.

(66) Basun, S.; Danger, T.; Kaplyanskii, A.; McClure, D.; Petermann, K.; Wong, W. Optical and photoelectrical studies of charge-transfer processes in $\mathrm{YAlO}_{3}: \mathrm{Ti}$ crystals. Physical Review B 1996, 54, 6141.

(67) Batyaev, I.; Kobezhikov, Y. G. Physicotechnical and spectroscopic characteristics of titanium in aluminaphosphate phosphors. Technical Physics 2003, 48, 889-892.

(68) Grinberg, M.; Mandelis, A.; Fjeldsted, K.; Othonos, A. Spectroscopy and analysis of radiative and nonradiative processes in $\mathrm{Ti}^{3+}: \mathrm{Al}_{2} \mathrm{O}_{3}$ crystals. Physical Review $B$ 1993, 48, 5922 .

(69) Gualtieri, A.; Norby, P.; Hanson, J.; Hriljac, J. Rietveld Refinement using Synchrotron X-ray Powder Diffraction Data Collected in Transmission Geometry using an ImagingPlate Detector: Application to Standard m-ZrO $\mathrm{rO}_{2}$. Journal of Applied Crystallography 1996, 29, 707-713.

(70) Krukau, A. V.; Vydrov, O. A.; Izmaylov, A. F.; Scuseria, G. E. Influence of the exchange screening parameter on the performance of screened hybrid functionals. The Journal of Chemical Physics 2006, 125, 224106.

(71) Jiang, H.; Gomez-Abal, R. I.; Rinke, P.; Scheffler, M. Electronic band structure of zirconia and hafnia polymorphs from the $G W$ perspective. Physical Review $B \mathbf{2 0 1 0}$, 81, 085119.

(72) Dash, L. K.; Vast, N.; Baranek, P.; Cheynet, M.-C.; Reining, L. Electronic structure and electron energy-loss spectroscopy of $\mathrm{ZrO}_{2}$ zirconia. Physical Review B 2004, 70, 245116. 
(73) Yildirim, H.; Pachter, R. Extrinsic Dopant Effects on Oxygen Vacancy Formation Energies in $\mathrm{ZrO}_{2}$ with Implication for Memristive Device Performance. ACS Applied Electronic Materials 2019, 1, 467-477.

(74) Akiyama, M.; Xu, C.-N.; Nonaka, K. Intense visible light emission from stress-activated $\mathrm{ZrO}_{2}$ :Ti. Applied Physics Letters 2002, 81, 457-459.

(75) Lu, X.; Liang, K.; Gu, S.; Zheng, Y.; Fang, H. Effect of oxygen vacancies on transformation of zirconia at low temperatures. Journal of Materials Science 1997, 32, 6653-6656.

(76) Fabris, S.; Paxton, A.; Finnis, M. W. A stabilization mechanism of zirconia based on oxygen vacancies only. Acta Materialia 2002, 50(20), 5171-5178.

(77) Shukla, S.; Seal, S. Mechanisms of room temperature metastable tetragonal phase stabilisation in zirconia. International Materials Reviews 2005, 50, 45-64.

(78) Camagni, P.; Samoggia, G.; Sangaletti, L.; Parmigiani, F.; Zema, N. X-rayphotoemission spectroscopy and optical reflectivity of yttrium-stabilized zirconia. Physical Review B 1994, 50, 4292-4296.

(79) Zottnick, S. H.; Sorg, J. R.; Müller-Buschbaum, K.; Fouassier, C. Encyclopedia of Inorganic and Bioinorganic Chemistry; American Cancer Society, 2019; pp 1-22.

(80) Carvalho, J. M.; Rodrigues, L. C.; Felinto, M. C.; Nunes, L. A.; Hölsä, J.; Brito, H. F. Structure-property relationship of luminescent zirconia nanomaterials obtained by sol-gel method. Journal of Materials Science 2015, 50, 873-881.

(81) Matsuzawa, T.; Aoki, Y.; Takeuchi, N.; Murayama, Y. A New Long Phosphorescent Phosphor with High Brightness, $\mathrm{SrAl}_{2} \mathrm{O}_{4}: \mathrm{Eu}^{2+}, \mathrm{Dy}^{3+}$. Journal of The Electrochemical Society 1996, 143, 2670.

(82) Momma, K.; Izumi, F. VESTA 3 for three-dimensional visualization of crystal, volumetric and morphology data. Journal of Applied Crystallography 2011, 44, 1272-1276. 


\section{${ }_{587}$ Table of Contents (TOC) graphic}

We performed point defect calculations using DFT to demonstrate the easy stabilization of $\mathrm{Ti}^{4+}$ on $\mathrm{Zr}$ sites within the $\mathrm{m}-\mathrm{ZrO}_{2}$ : Ti compound and its major role in luminescent properties.
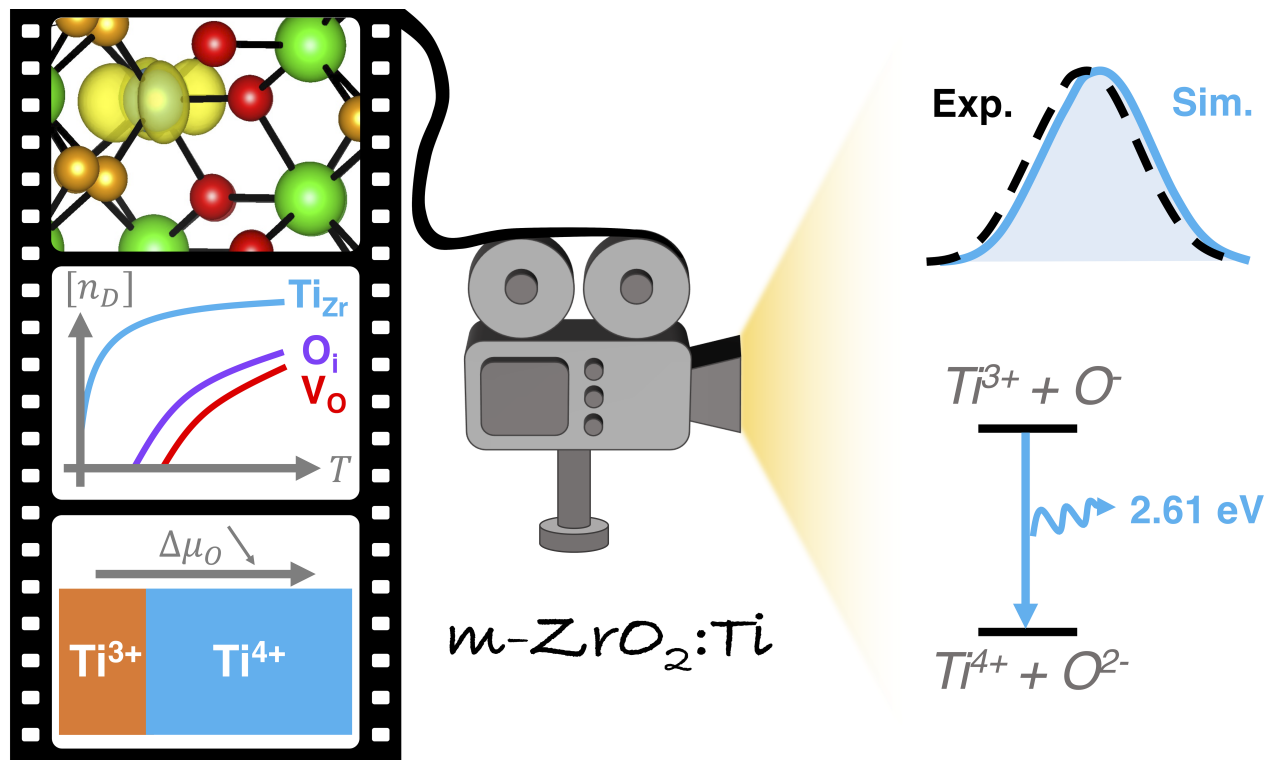